\title{
Investigation on single-particle impact breakage functions of a « shaba » hybrids variety of maize kernel by drop-weight technique
}

\author{
Kengne Benjamin*, Ndibi Mbozo'o Martin Paul", Samon Jean Bosco*, Nzie Wolfgang**, Tcheukam-Toko \\ Dénis $^{* * *}$ and Ali Ahmed ${ }^{* * * * *}$ \\ * Departement of Mechanical Engineering, ENSAI of Ngaoundere \\ ** Departement of Fundamentals Sciences and Engineering Techniques, EGCIM of Ngaoundere \\ *** Departement of Mechanical Engineering, ENSET of Kumba \\ *** Departement of Food engineering and Quality control, IUT of Ngaoundere
}

DOI: 10.29322/IJSRP.11.11.2021.p11940

http://dx.doi.org/10.29322/IJSRP.11.11.2021.p11940

\begin{abstract}
Physical properties and impact breakage functions for a «Shaba » variety hybrid of maize kernel was estimated. About the investigation of impact breakage functions, a new modified manual version of a JK Tech drop-weight test device was used. The purpose of this research is to investigate the effect of specific comminution energy (Ecs) on impact breakage distributions. The main results in this study can be summarized as follows : for physical properties of maize kernels : length (L), width (1), and thickness (E) was 12.56, 9.67, and $4.83 \mathrm{~mm}$ respectively, the geometric mean diameter (Dg) $8.32 \mathrm{~mm}$, arithmetic diameter (Da) $9.03 \mathrm{~mm}$, equivalent diameter (Dp) $8.72 \mathrm{~mm}$, the percentage of sphericity (Sp) is $66.76 \%$ and the mass of 1000 maize grains is 359.43 gr. For impact breakage distributions, relationship between specific comminution energy and grindability index $\left(\mathrm{t}_{10}\right)$ was establised. Ecs - $\mathrm{t}_{10}$ model given in the literature was successfully fitted to the single impact breakage test results, the value of constant was respectively $\mathrm{A}$ and $\mathrm{b}$. And in the end of this research, t-family curve approach was established to estimate single particle breakage functions of the «Shaba» variety hybrid maize kernel.
\end{abstract}

Keywords : «Shaba» variety, comminution, modeling, girndability index, drop-weight test.

\section{INTRODUCTION}

Maize is the most commonly used cereal in animal feed in worldwide [1], particularly in African country. This is one of the reasons why production has doubled in the last few years. It is, after wheat and rice, the most important cereal grain in the world, providing nutrients for humans and animals and serving as a basic raw material for the production of flour, grits, animal feed, alcoholic beverages, breakfast cereal and other food ingredients, such as corn-meal and food sweeteners proceeding by the dry milling process [2]. It is generally preferred over other cereal grains because it has a more uniform nutritive value and provides a better structure to the feed, which might favor feed intake in poultry [3].

The major steps involved in the processing of maize are harvesting, drying, dehusking, shelling, storing, and milling. The most important processing step is the comminution process and the most commonly post harvest equipment is comminution equipment. Communition or grinding is a unit operation widely used in the food industry and designed to reduce the size of materials to give a usable form or to separate their components. This process is generally carrying out by locally fabricated equipment in Cameroon and it is energetic consuming. The performance optimization (energetic consuming and particle size distribution of ground particle) of grinding machine need first to understand the comportement of physical and breakage characteristics of grinding feed. It is, therefore, necessary to determine the properties of grinding feed in order to provide the much needed data for the designing of grinding machine. Modelization of comminution equipment [4] require the determination of breakage distribution function. This can be determined by using different methods such as single particle breakage test [5] and one-size fraction batch grinding test, back-calculation [6].

The breakage rate of maize kernels is an important index to measure the performance of post - harvest equipement of maize [7]. Therefore, it is of great research significance to improve the detection accuracy of maize kernels breakage, which is an important way to improve post - harvest performance. Specific breakage function and grindability index of materials is frequently assumed to be independent of process conditions ([8] [9] [10]), initial particle size, and input energy level [11], which all seemed to be made to ease the research of comminution modelling. In another way, many other researchers proved the opposite case ([12] [13] [14]). Previous and past studies show that moisture, components (starch, protein, and oil) and physical and mechanical properties are potential variables that can be used to predict breakage rate and then give guidance for harvest time ([15] [16] [17]).

Twin-pendulum and drop-weight devices were used to develop standard procedures for the calculation of breakage functions ([5] [9]; [16]). In a drop-weight ([19] [20]) the material to be broken rests on a rigid anvil and is impacted by a drop down object (a falling mass) so that the material is compressed between the anvil and the falling mass. Many researchers found that particles of a given size generally have a range of strengths, so that the forces generated by an impact of energy can break some particles and leave others unbroken [11] [21]. Specific breakage function can be estimated by using the relationship between specific comminution energy $(\mathrm{kWh} / \mathrm{t})$ and $\mathrm{t}_{10}$ grindability index $(\%)$ and $\mathrm{t}$-curve approach which were described by Narayanan [5] [9]. Over two decades, numerous drop weight tests have been conducted to characterise the 
impact cereal kernel hardness. These data have been used to fit the parameters $A$ and $b$, and the product Axb has been used as an indicator of cereal kernel hardness. It is popular nowadays for many post - harvesting grinding processing engineers and researchers to use the $\mathrm{A}$ and $\mathrm{b}$ parameters in the $\mathrm{t}_{10}$ versus Esc curve, in their comminution circuit design, simulation, optimisation and operation.

The breakage susceptibility of maize grain is moisture dependent as reported by Paulsen [22]. Thus, it has been recommended that the moisture content of the sample around 12 to $13 \%$ should be consistent and reported together with the percentage breakage when grain is tested. Narayanan says that t-curve approach is using to normalize the effect of particle size distribution []. Different breakage energy levels were proposed for the estimation of breakage distribution function in the literature.

However, due to the diverse climatic types and regional differences in agricultural development and equipement design, the diffusion of this technology is limited [22].

In this study, the aim is to measure the physical properties of the «Shaba» variety hybrid maize kernel which affect on grinding breakage charcteristics, and to evaluate breakage distributions of different size fractions of maize kernels by drop-weight technique at differents specific impact energy levels; in another way, to normalize the size effect by using the t-curve approach in estimating the breakage functions. Ecs$\mathrm{t}_{10}$ model [5] was obtained following the breakage test results. the overall relationship between specific comminution energy and grindability index $\left(\mathrm{t}_{10}\right)$ was used to estimate breakage functions for hybrib variety maize kernels at different specific comminution energy levels. And in the end reakage function reconstructions models ( $\mathrm{t}_{10}$ - tn models) were proposed for «Shaba » variety hybrid maize kernel comminution modelling.

\section{MATERIAL AND METHODS}

\section{1 «Shaba » variety of hybrid maize kernel}

One variety of maize hybrid «Shaba (figure 1) was selected based on constant availability and regularly use by millers in Adamaoua region. these were obtained in the Ngaoundere city market for this study during the period of May to June 2021.

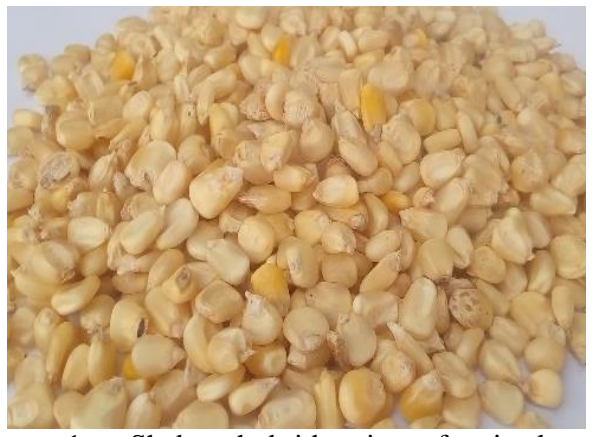

Figure 1 : «Shaba » hybrid variety of maize kernel

\subsection{Physical characteristics of maize kernel}

The physical characteristics of the maize (hybrids variety Shaba) kernels were obtained at mean moisture content 13,5\% w.b. A moisture meter (Smartsensor AR991) was used for controlling the maize kernels moisture content. Some physical properties of corn kernels that are related to the grinding process were measured with vernier calliper (measuring range $0-150 \mathrm{~mm}$ with an accuracy of $\pm 0.02 \mathrm{~mm}$ ). Kernel length ( $\mathrm{L}$ in $\mathrm{mm}$ ), width ( $\mathrm{W}$ in $\mathrm{mm}$ ) and thickness ( $\mathrm{T}$ in $\mathrm{mm}$ ) were measured with three replicates on randomly selected 100 maize kernel. The masse of 1000 maize kernels taken at random, was weighed by an electronic digital balance ranged from 0 to $5 \mathrm{~kg}$ max with accuracy of $0.01 \mathrm{~g}$.
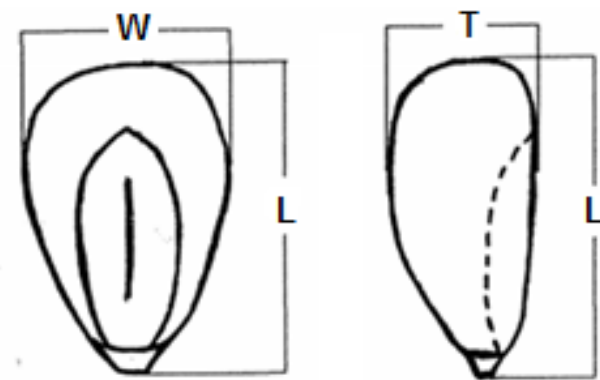

Figure 2 : Measured dimensions of maize kernel

The geometric mean diameter Dg, equivalent diameter Dp and arithmetic diameter $\mathrm{Da}$, in $\mathrm{mm}$ were calculated by using the geometric mean and arithmetic mean of the three axial dimensions, therefore using these equations [24] :

$$
\begin{aligned}
& D_{g}=(L W T)^{1 / 3} \\
& D_{p}=\left[L \frac{(W+T)^{2}}{4}\right]^{1 / 3} \\
& D_{a}=\frac{(L+W+T)}{3}
\end{aligned}
$$

The sphericity ( $\mathrm{Sp}$ ) of kernel, defined as the ratio of the surface area of the sphere having the same volume as that of grain to the surface area of grain, was calculated by using the following equation, developed by Moshenin [24] :

$$
S_{p}=\frac{(L W T)^{1 / 3}}{L}
$$

\subsection{Drop-Weight Test Device}

Drop-weight test device which was used in this study was previously described by Genç et al., [6] [25]. It mainly comprises of a steel anvil, falling mass in plate shape using as drop weight head, an electromagnet through which an electromagnetic field is formed so that weight can be held or released from the desired heights. A picture of the drop weight device is given in Figure 3.

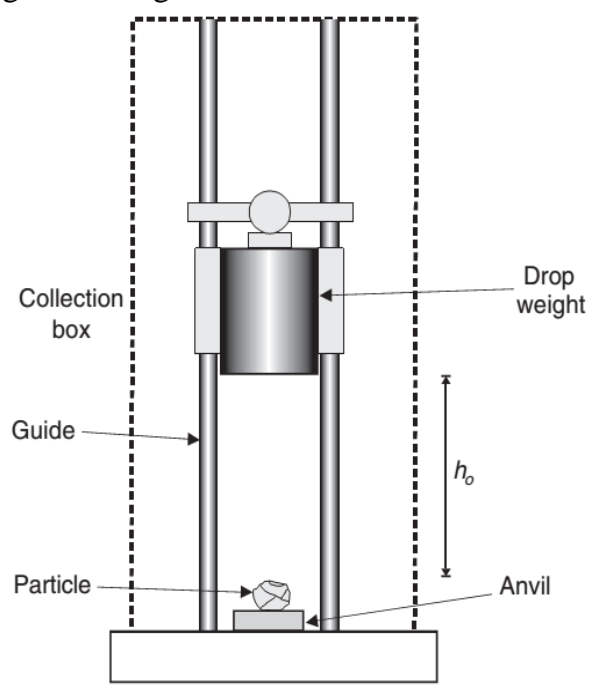

Figure 3 Modified Drop-weight test device

Impact energy level supplied by the falling mass was calculated by equation (5) and the specific comminution energy level was calculated by equation (6) [4].

$$
E_{i}=3600000 m_{d} g h_{0}
$$

where,

Ei : Impact breakage energy $(\mathrm{kWh})$

$\mathrm{m}_{\mathrm{d}}$ : Mass of drop weight head $(\mathrm{kg})$

$\mathrm{g}:$ gravity acceleration $\left(\mathrm{m} . \mathrm{s}^{-1}\right)$ 
$\mathrm{h}_{0}$ : Differentiel height of the falling mass above the anvil (m)

$$
E_{c s}=\frac{E_{i}}{m_{p}}
$$

where,

Ecs : Specific comminution energy $(\mathrm{kWh} / \mathrm{t})$

$\mathrm{m}_{\mathrm{p}}$ : Mean particle mass $(\mathrm{t})$

\subsection{Experiments}

Differents Tests were conducted on five size fractions of maize kernels ( $<6 \mathrm{~mm}, 6-8 \mathrm{~mm}, 8-10 \mathrm{~mm}, 10-12 \mathrm{~mm}$ and $>12 \mathrm{~mm})$ at different specific comminution energy levels $(\mathrm{kWh} / \mathrm{t})$. Number of particles in each test size fraction was equal to 30 and the mean mass of the maize kernels were determined before grinding by weighing on laboratory balance. Appropriate height and drop weights were calculated to determine the specific comminution energy levels used for breakage. Impact energy supplied by the falling mass is calculated from the given equation (6).

Single particle breakage tests were conducted on each sample at the required energy levels. All broken fragments of maize kernels were collected from each breakage test, and dry sieved with four sieves $(2 \mathrm{~mm}, 1.6 \mathrm{~mm}, 1 \mathrm{~mm}$ and $0.5 \mathrm{~mm}$ ) during a period of 1 minute in a J-tronic shaker. Test feed fractions size, specific comminution energy levels (Ecs) in $\mathrm{kWh} / \mathrm{t}$ and number of particles to break are collected in Table 1.

Table 1 Drop-weight test specifications

\begin{tabular}{|c|c|c|c|c|c|c|c|c|c|c|c|c|c|c|c|}
\hline $\begin{array}{c}\text { Test size fraction } \\
(\mathrm{mm})\end{array}$ & \multicolumn{9}{|c|}{$>12 \mathrm{~mm}$} & \multicolumn{10}{c|}{$10-12 \mathrm{~mm}$} & \multicolumn{2}{c|}{$8-10 \mathrm{~mm}$} & \multicolumn{2}{c|}{$6-8 \mathrm{~mm}$} & \multicolumn{1}{c|}{$<6 \mathrm{~mm}$} \\
\hline Number of particles & \multicolumn{10}{|c|}{50} \\
\hline $\mathrm{h}_{0}(\mathrm{~m})$ & 0,1 & 0,25 & 0,4 & 0,1 & 0,25 & 0,4 & 0,1 & 0,25 & 0,4 & 0,1 & 0,25 & 0,4 & 0,1 & 0,25 & 0,4 \\
\hline
\end{tabular}

\subsection{Ecs- $t_{10}$ Size Model}

The value of grindability index $\mathrm{t}_{10}$ was used as the fineness or breakage index number. Many authors were defined $t_{10}$ like the amount of material passing $1 / 10^{\text {th }}$ of the geometric mean of the broken size fraction. The value of grindability index $t_{10}$ indicates the fineness of the broken grain size fraction for different specific energy consumption levels. Ecs- $t_{10}$ model is given in Equation (7).

$$
\boldsymbol{t}_{10}=A\left[1-\exp \left(-b E_{c s}\right]\right.
$$

In this breakage model ;

$\mathrm{A}, \mathrm{b}:$ is material impact parameters. A $(\%)$ and $\mathrm{b}\left[\mathrm{t} .(\mathrm{kWh})^{-1}\right]$ are the grain impact breakage parameters, which can be fitted to grain breakage testing data.

Ecs : specific comminution energy $\left(\mathrm{kWh} \cdot \mathrm{t}^{-1}\right)$

When the relationship between $t_{10}$ and specific comminution energy level is determined, specific energy consumption required to break the grain into the desired particle size distribution can be predicted using t-curves. The product of material impact parameter Axb can be used to characterize the hardness of the maize kernels, so it is an indicator of material resistance to breakage. If the value of $\mathrm{Axb}$ is low that mean that more energy is needed for an equivalent amount of breakage, that indicating a matrial have high resistance to breakage [4]. The relationship between $t_{10}$ and $t_{n}$ is expressed values where $n=2,4,25,5075$.

\section{RESULTS AND DISCUSSION}

\subsection{Maize grain physical characteristics}

Table 2 belows shows the physical characteristics of maize hybrid «Shaba». The average dimensions of 100 maize kernels at a mean moisture content of $13,5 \%$ w.b. were : length $12.56 \mathrm{~mm}$, width $9.67 \mathrm{~mm}$, and thickness $4.83 \mathrm{~mm}$. The geometric mean diameter of corn grains increased from 7.2 to $7.78 \mathrm{~mm}$ and arithmetic diameter from 7.79 to $8.43 \mathrm{~mm}$. In addition we obtained an average mass of 353.49 gr par 1000 «shaba» maize grains. From the value of $\mathrm{L}, \mathrm{W}$ and $\mathrm{T}$, we calculated the diametrs and the sphericity of corn grains using equation 1, 2, 3 and 4 is $66.76 \%$. the mean values $\mathrm{Dg}$, Da and $\mathrm{Dp}$ of 100 maize kernels is respectively equal to $8.32,9.03$ and 8.72 .

Tableau 2 : Physical characteristics of maize hybrid «Shaba»

\begin{tabular}{ccccccccc}
\hline & $\begin{array}{c}\mathrm{L} \\
(\mathrm{mm})\end{array}$ & $\begin{array}{c}\mathrm{W} \\
(\mathrm{mm})\end{array}$ & $\begin{array}{c}\mathrm{T} \\
(\mathrm{mm})\end{array}$ & $\begin{array}{c}\mathrm{Dg} \\
(\mathrm{mm})\end{array}$ & $\begin{array}{c}\mathrm{Da} \\
(\mathrm{mm})\end{array}$ & $\begin{array}{c}\mathrm{Dp} \\
(\mathrm{mm})\end{array}$ & $\begin{array}{c}\text { Sp } \\
(\%)\end{array}$ & $\begin{array}{c}\text { Mass of 1000 } \\
\text { grains }(\mathrm{g})\end{array}$ \\
\hline Min & 9,48 & 706 & 3,42 & 6,99 & 7,21 & 7,05 & 53,94 & 355,75 \\
Max & 15,4 & 11,50 & 9,60 & 11,06 & 11,13 & 11,09 & 84,40 & 363,9 \\
Mean & 12,56 & 9,67 & 4,83 & 8,32 & 9,03 & 8,72 & 66,76 & 359,43 \\
Standard deviation & 1,237 & 0,942 & 1,041 & 0,649 & 0,628 & 0,630 & 7,02 & 2,55 \\
\hline
\end{tabular}

Results differ a little from those from litterature [16] [29]. The measured values for length, width and thickness of the 100 maize kernels tested of the «shaba» variety a within a normal distribution. This result was confirmed by the pierson chi square test at the confident interval of 0,95 . The 1000 grain mass values of the samples analysed oscillate between 355.75 and 363,9 gr. These values are closed to hybrid varieties cultivated in the sahelien zone [27].
Particle size distributions of the maize flour i.e the broken maize kernels particles are given in Figure 5 to 9 for different specific communition energy levels.

Particle size distributions of the broken maize kernels in the breakage event of feed size fraction $>12 \mathrm{~mm}$ indicated that finer particle size distribution could be obtained as the level of specific communition energy was increased.

\subsection{Impact Particle Size Distributions}




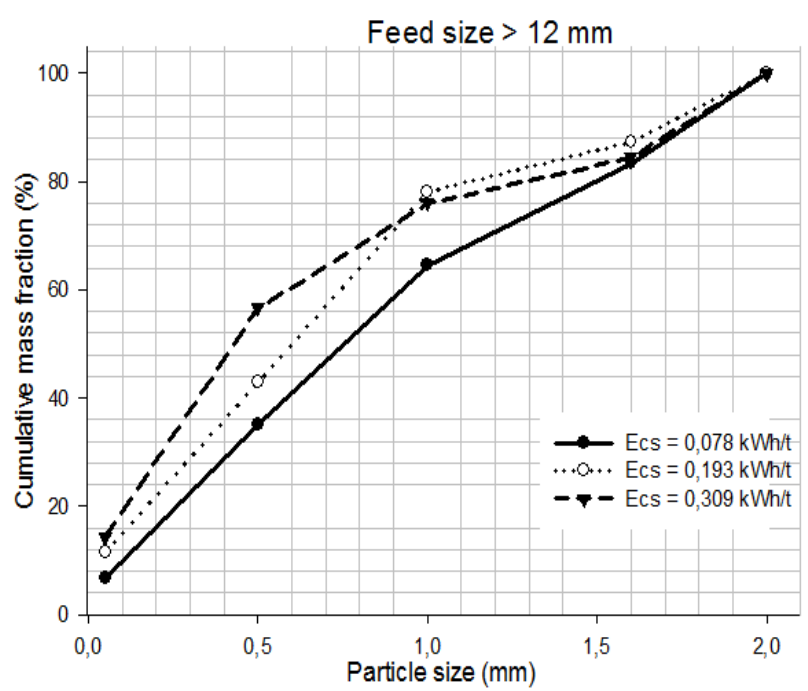

Figure 5 Size distributions of particles from the breakage of feed size $>12 \mathrm{~mm}$ at different specific communition energy levels

Feed size $[10,12[$

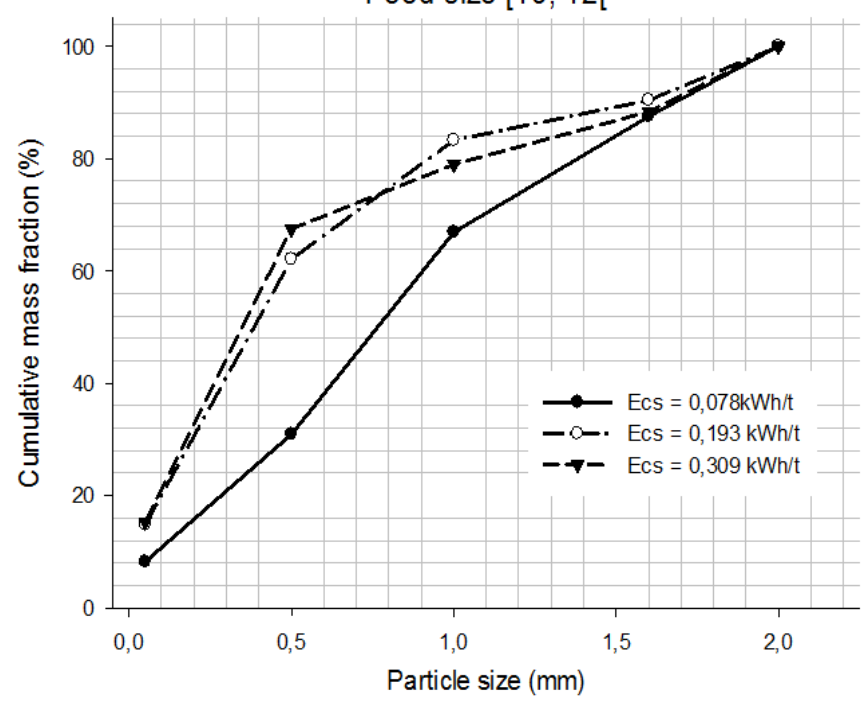

Figure 6 Size distributions of particles from the breakage of feed size $[10 ; 12[\mathrm{~mm}$ at at different specific communition energy levels

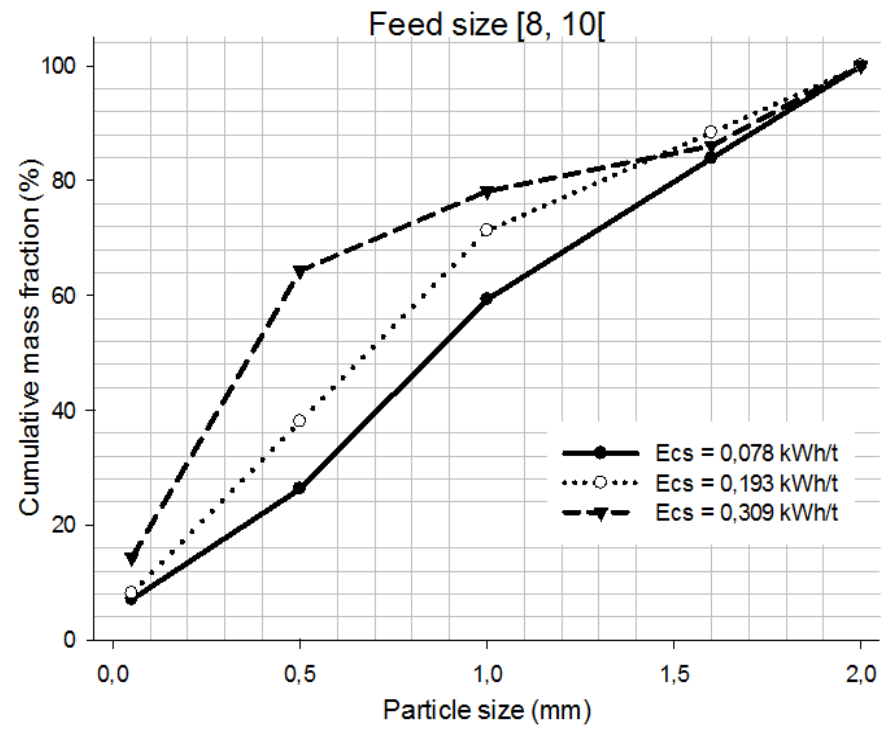

Figure 7 Size distributions of particles from the breakage of feed size

$[8 ; 10[\mathrm{~mm}$ at different specific communition energy levels

It was observed that, breakage maize kernel size distributions did not change significantly although the specific communition energy level was increased which could be observed from the size distributions of product particles from the breakage of feed size $[6 ; 8$ [ at specific communition energy levels of 0,078 $\mathrm{kWh} / \mathrm{t}$ and 0,193 kWh/t (Figure 8).

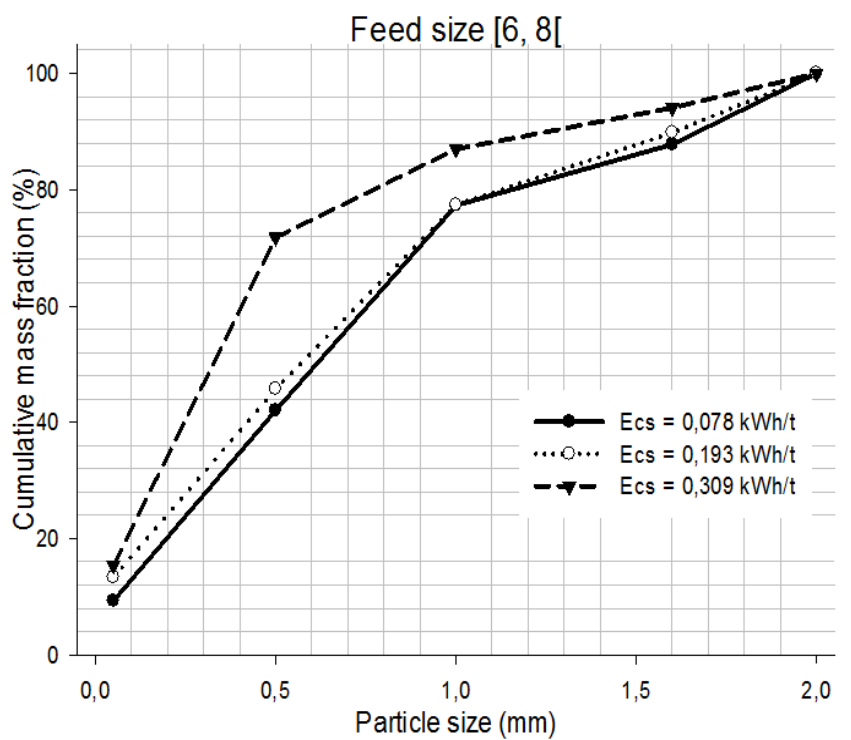

Figure 8 Size distributions of particles from the breakage of feed size [6;8[ at different specific communition energy levels

We observed that it became difficult to break maize kernels by impact as the grain size decreased. For example, closely similar breakage product size distributions were observed in the breakage event of particles within the feed size $<6 \mathrm{~mm}$, although the specific communition energy level was grown (Figure 9) which indicated that no more considerable size reduction would happen.

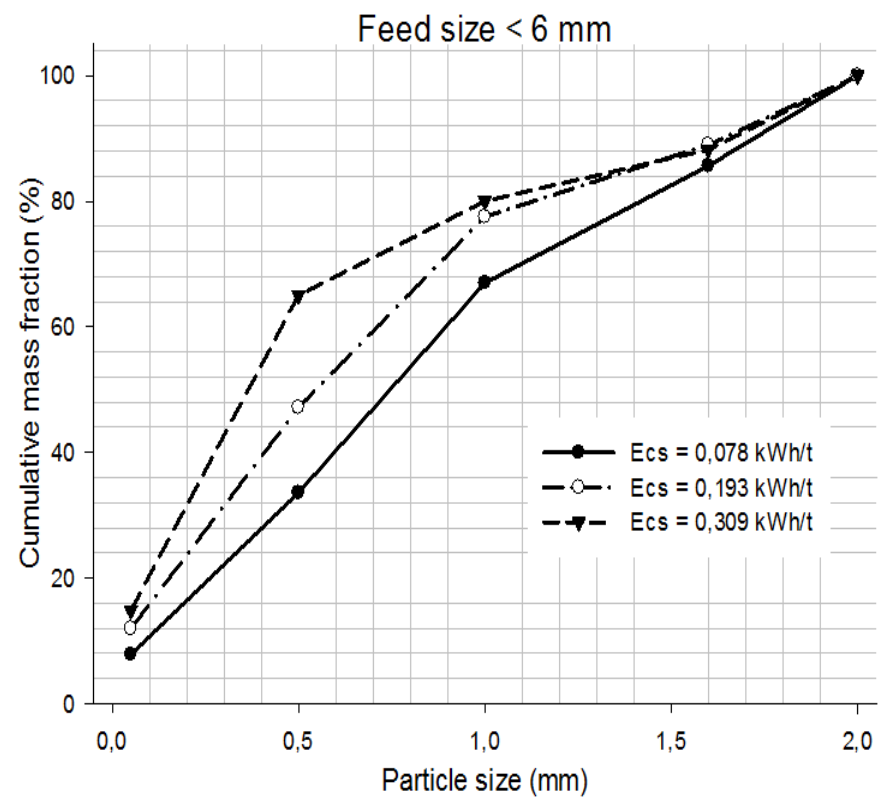

Figure 9 Size distributions of particles from the breakage of feed size $<6 \mathrm{~mm}$ at different specific communition energy levels

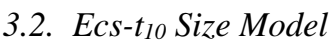

When the relationship between $\mathrm{t}_{10}$ and specific comminution energy level is established, specific energy consumption required to achieve the desired particle size distribution can be predicted using $\mathrm{t}$-curves. Ecs - $\mathrm{t}_{10}$ model is given in equation (8). The product of model parameters A and b is the slope of the relation at 'zero' input energy. 


$$
t_{10}=59,65\left[1-\exp \left(-9,026 \times E_{c s}\right)\right] \quad \mathrm{R}^{2}=0,85
$$

$\mathrm{A}$ and $\mathrm{b}$ values were determined by nonlinear regression using SigmaPlot statistical program. $\mathrm{R}^{2}$ of the overall model fit was 0.85 .

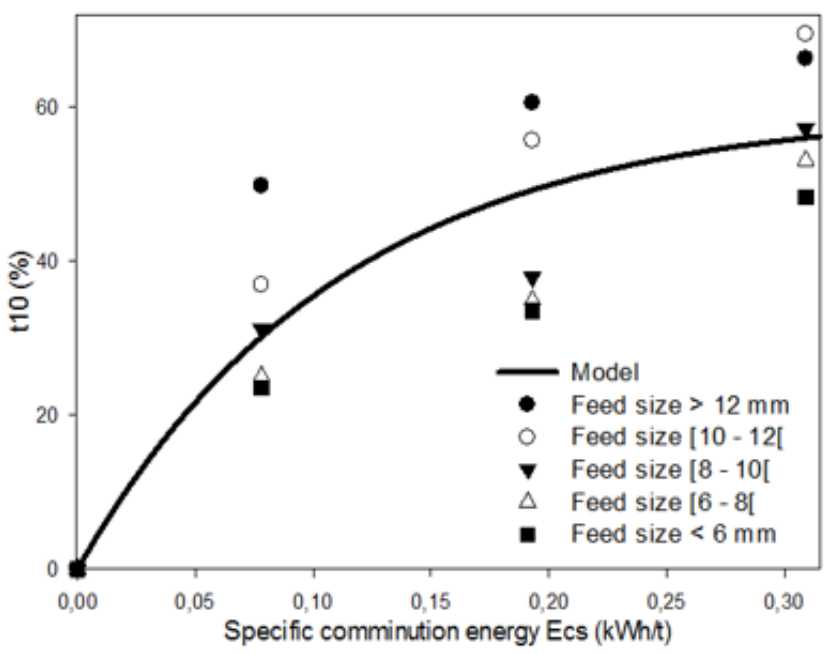

Figure 10 Overall relationship between specific comminution energy and $t_{10 \%}$ for the hybrid maize kernel sample

Overall relationship between specific comminution energy and $t_{10}$ parameter is given in Figure 10. It is obvious that larger particles produce a higher $t_{10}$ when subjected to the same specific energy. Experimental values were plotted as compared to model calculated values (model fit). Sufficiently good agreement between the experimental and model fitted values were observed which showed the validation of the Ecs- $t_{10}$ model for the hybrid maize kernel.

Non-linear regression analysis was performed on the test results of each test size fraction to establish the Ecs - $t_{10}$ relationship by particle size.

Model validation results for different size fractions are tabulated in Table 3. This Table shows that the Axb values generally increase with particle size, which confirms the particle size effect on breakage. But the value of feed size [8 ; 12[ isn't in the same logic, this can be explained by some incoclusie tests during the experiments. However, the fitted $b$ values for the individual size fractions varies irregularly. This gives rise to difficulties in estimating the model parameters for the untreated size fractions from the calibrated size-specific model parameters in simulations.

Table 3 Estimated model parameters for different particle size

\begin{tabular}{|c|c|c|c|c|}
\multicolumn{5}{|c|}{ fractions } \\
\hline Feed size & A & $\mathrm{b}$ & $\mathrm{R}^{2}$ & Axb \\
\hline$>12 \mathrm{~mm}$ & 64,69 & 18,29 & 0,99 & 1183,18 \\
\hline$[10 ; 12[$ & 73,52 & 8,28 & 0,99 & 608,75 \\
\hline$[8 ; 12[$ & 59,61 & 7,27 & 0,94 & 433,62 \\
\hline$[6 ; 8[$ & 51,65 & 9,16 & 0,93 & 473,11 \\
\hline$<6 \mathrm{~mm}$ & 52,09 & 7,21 & 0,98 & 375,05 \\
\hline
\end{tabular}

A linear relationship was found to exist between particle size and Axb parameter which provided comparison between the hardness of different particle sizes (Figure 12). Findings also indicated that, Ecs- $\mathrm{t}_{10}$ relationships of «Shaba » hybrid maize kernels particles vary by particle size for a constant level of specific comminution energy which may be linked to the probable differences in microstructure, mineralogical and chemical composition of different particle sizes.

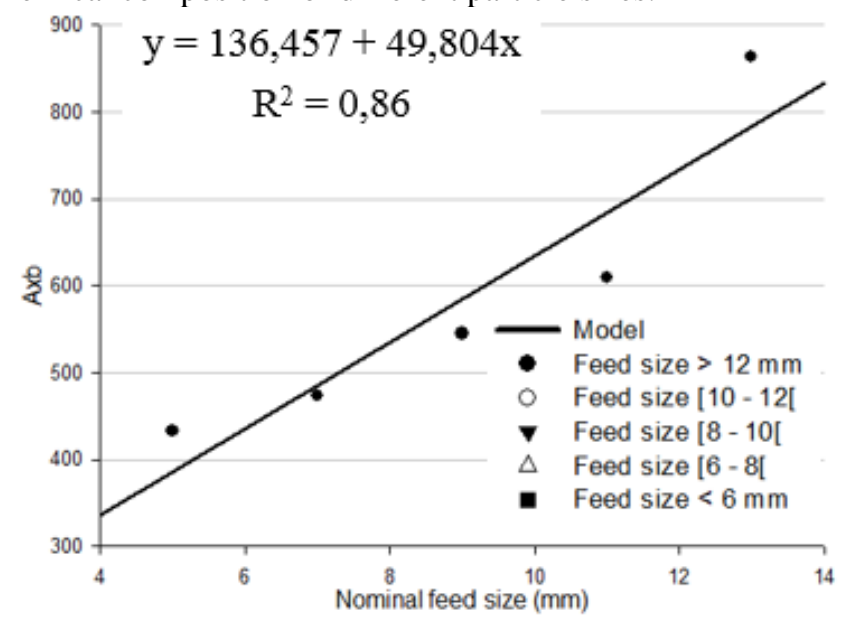

Figure 12 Relationship between particle size and Axb

$\mathrm{Axb}$ parameter can be used to characterize the hardness of the maize kernels. Lower value of $\mathrm{Axb}$ indicates that more energy is needed for an equivalent amount of breakage [4].

\section{3. t-family Curves and Models}

t-family curve approach [5] was used to determine breakage functions of the gold ore. $\mathrm{t}_{10}-\mathrm{tn}$ relationships are given in Figure 13 for breakage function reconstruction. Description of the t-curve approach which normalizes the effect of particle size was given in the literature [5] [8].

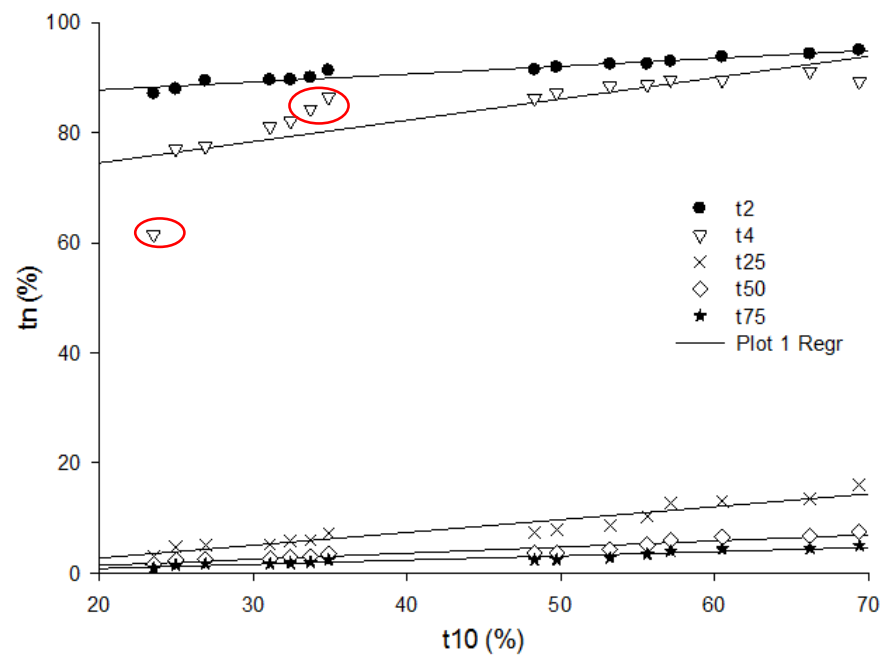

Figure $13 \mathrm{t}_{10}$-tn family relationships for the hybrid maize kernel

Distribution parameter, $t_{10}$ was used which represents the amount of material at fine size ranges thus provides more information on the fragmentation at fine sizes. According to this approach, particle size distribution data obtained after the breakage of test samples was plotted and the size distribution parameters $t_{2}, t_{4}, t_{10}, t_{25}, t_{50}$, and $t_{75}$ correspondingly expressing the cumulative per cent passing size of $y / 2, y / 4, y / 10, y / 25$, $y / 50, y / 75$ were determined where $y$ is the geometric mean of the feed size fraction for the test particles [6] [27]. $t_{10}$ versus other distribution parameters are plotted to obtain t-family curves through which the product size distribution resulting from the breakage of the considered size fraction at any specific comminution energy level can be established. $\mathrm{t}_{10}-$ 
tn family curves for the gold ore are given in Figure 9. Regression equations of the t-curves are tabulated in Table 4.

Table 4 Normalized breakage function re-construction models

\begin{tabular}{|c|c|}
\hline Equation & $\mathbf{R}^{\mathbf{2}}$ \\
\hline$t_{2}=84,89+0,143 t_{10}$ & 0,94 \\
\hline${ }^{*} t_{4}=69,195+0,338 t_{10}$ & 0,94 \\
\hline$t_{25}=-1,957+0,233 t_{10}$ & 0,91 \\
\hline$t_{50}=-0,827+0,111 t_{10}$ & 0,91 \\
\hline$t_{75}=-0,694+0,0765 t_{10}$ & 0,90 \\
\hline
\end{tabular}

Three values corresponding to the circled points in figure 13 were exclued to $t_{4}-t_{10}$ regression to obtain an acceptable $R^{2}$.

Single particle impact breakage functions of the «shaba» variety of maize kernels were estimated for different specific energy levels using the regression equations in Table 4 and given in Figure 15. It was observed that that describe well the particle size distribution of «shaba» variety ground maize. It was also observed that, maize kernels started to exibit similar breakage functions at impact energy levels higher than $1 \mathrm{kWh} / \mathrm{t}$ which indicated that no more considerable size reduction could be achieved at energy levels higher than $1 \mathrm{kWh} / \mathrm{t}$ by impact mechanism.

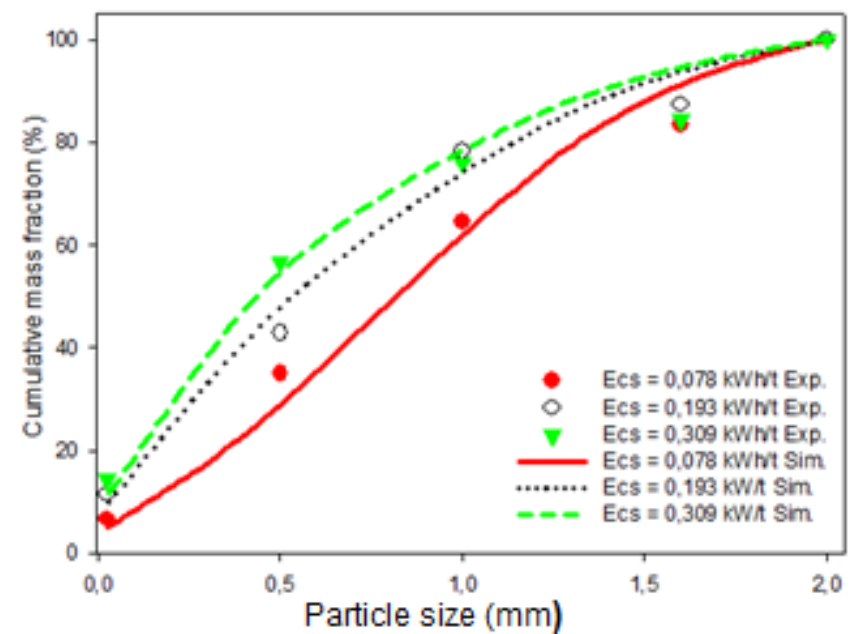

Figure 15 Typical impact breakage functions for different specific comminution energy levels for feed size $>12 \mathrm{~mm}$, experimental and simulation

\section{CONCLUSION}

Using a new Drop - weigt equipement, the breakage of maize kernel was studied, and relationship between specific comminution energy and $t_{10}$ breakage distribution parameter for the «shaba» variety of maize kernels was found. That relationship was successfully fitted to the Ecs- $\mathrm{t}_{10}$ model given in the literature [4]. Impact breakage of maize kernels particles were found to be size and energy dependent. A linear relationship was found to exist between particle size and $\mathrm{Axb}$ impact breakage parameter. t-curves for «shaba » variety of maize kernels were modelled and proposed to reconstruct breakage functions which can be used in modelling of maize comminution. Variation in normalized breakage distribution functions were determined for different energy levels. Impact breakage distribution function was found to not change considerably at energy levels higher than $1 \mathrm{kWh} / \mathrm{t}$. Breakage function reconstruction models obtain by empirical method were proposed to be used in comminution modelling and simulations of size reduction machines operating on the basis of the impact mechanism in the processing of the related maize kernels.

\section{References}

[1] Y. Singh, V. Ravindran, T.J. Wester, A.L. Molan, G. Ravindran, Influence of feeding coarse corn on performance, nutrient utilization, digestive tract measurements, carcass characteristics, and cecal microflora counts of broilers, Pultry Sci. 93 (2014) 607-616

[2] A. O. Atere, O. J. Olukunle, A. P. Olalusi, O. C. Ademosun. Optimizing the milling efficiency of hammer mill for maize processing using response surface methodology (RSM) J. of Multidisciplinary Engineering Science and Technology 3 (3), 2016, pp : 4161 - 4165. ISSN: 2458-9403.

[3] Mohamed I. Shoughy, Sammy A. Marey, Abbas A. El-Shenawy. Effect of drying temperatures on stress cracks and breakage suseptibility of corn grains. Misr J. Ag. Eng., 26 (1), 2009, pp : 453 - 468.

[4] Napier Munn, T. J., Morrell, S., Morrison, R.D., Kojovic, T. Mineral Comminution Circuits Their Operation and Optimization. JKMRC Monograph Series in Mining and Mineral Processing, No.2, The University of Queensland, Brisbane, 2005, Australia.

[5] Narayanan, S. S. Development of a laboratory single particle breakage technique and its application to ball mill modelling and scale-up. PhD Thesis. Julius Kruttschnitt Mineral Research Centre, The University of Queensland, 1985, Australia.

[6] Genç, Ö. An investigation of the breakage distribution functions of clinker and additive materials. MSc Thesis. Hacettepe University, Mining Engineering Department, 2002, Turkey.

[7] Liang Yang, Zhuo Wang, Lei Gao, and Xiaoping Bai. Detection of maize kernels breakage rate based on K-means clustering. AIP Conference Proceedings 1834, 030025 (2017);

[8] Austin, L. G., Luckie, P. T. Methods for determination of breakage distribution parameters. Powder Technology, 5, 1971, pp : 45-52.

[9] Narayanan, S. S. Single particle breakage tests: A review of principles and applications to comminution modeling. Bull Proc. Australas. Inst. Min. Metall. 291, 4, 1986, pp : 49-58.

[10] A. Pérez-Bonilla, M. Frikha, R.P. Lázaro, G.G. Mateos. Type of grinding of the main cereal of the diet affects production of brown egg-laying hens, Anim. Feed Sci. Technol. 194, 2014, pp : 121 -130.

[11] Austin, L. G., Weller, K. R. 1982. Simulation and scale-up of wet ball mills. XIV International Mineral Processing Congr., Toronto, Canada, 8.1-8.24.

[12] Hukki, R.T. Proposal for a Solomonic settlement between the theories of von Rittinger, Rick and Bond. Trans SME/AIME, 220, 1961, pp : 403-408.

[13] Schönert, K. Advances in comminution fundamentals and impacts on technology. Aufbereit.-tech. 32, 1991, pp : 487-494.

[14] Weedon, D. M. A perfect mixing matrix model for ball mills. Minerals Engineering. 14, 10, 2001, pp : 1225-1236.

[15] Singh, S., Finner, M., Rohatgi, P., Buelow, F., \& Schaller, M. Structure and mechanical properties of corn kernels: A hybrid composite material. Journal of Materials Science, 26, 1991, pp : 274-284.

[16] Mohammad Reza Seifi and Reza Alimardani. The Moisture Content Effect on Some Physicaland Mechanical Properties of Corn (Sc 704). Journal of Agricultural Science 2 (4), 2010, pp : 125 - 134.

[17] Wang, K. R., \& Li, S. K. Breakage rate of mechanical harvesting of maize kernels : A review.Scientia Agricultura Sinica, 50, 2017, pp : 2018-2026.

[18] Morrell, S., Man, Y. T. Using modelling and simulation for the design of full scale ball mill circuits. Miner. Eng. 10, 12, 1997, pp : 1311-1327.

[19] Shahbazi Feizollah, Valizade Saman, Dowlatshah Ali. Mechanical damage to green and red lentil seeds. Food Sci. Nutr. 5, 2017, pp : 943-947. Doi : $10.1002 /$ fsn 3.480

[20] Tavares, L. M., King, R. P. Single-particle fracture under impact loading. Int. J. Miner. Process. 54, 1998, pp : 1-28.

[21] Austin L. G. A treatment of impact breakage of particles. Powder Technology 126, 2002, pp : 85-90.

[22] Paulsen M. R.. Corn breakage susceptibility as a function of moisture content. ASAE Paper No. 82-3078, 1983, St. Joseph, MI.

[23] Wang, X. Y., Wang, X. L., Xu, C. C., Tan, W. M., Wang, P., \& Meng, Q. F. Decreased kernel moisture in medium-maturing maize hybrids with high yield for mechanized grain harvest. Crop Science, 59, 2019, pp : 2794-2805.

[24] Mohsenin, N. N. Physical Properties of Plant and Animal Materials, Gordon and Breach Science Publishers, New York, 1986.

[25] Javad Tarighi, Asghar Mahmoudi, and Naser Alavi. Some mechanical and physical properties of corn seed (Var. DCC 370). African Journal of Agricultural Research Vol. 6 (16), pp. 3691-3699. (2011).

[26] Goalbaye, T., Somo Toukam, M.G., Diallo, M.D., Hinnone Kapagnon, B., Cisse, A. Évaluation des performances agronomiques des variétés améliorées de maïs (Zea mays L.) en milieu paysan dans la zone soudanienne du Tchad. Journal of Animal \& Plant Sciences 41, 2019, pp : 6977-6988. 
[27] Genç Ö., Benzer A.H., Ergün Ş.L. Analysis of single particle impact breakage characteristics of raw and HPGR-crushed cement clinkers by drop weight testing. Powder Technology 259, 2014, pp : 37-45

\section{AUTHORS}

First Author - Kengne benjamin, PhD student, Departement of mechanical engineering of Ensai, University of Ngaoundere. benjaminkengne@gmail.com.

Second Author - Ndibi Mbozo'o Marin Paul, Lecturer, Departement of mechanical engineering of Ensai, University of Ngaoundere.martinpaulnm@gmail.com

Third Author - Samon Jean Bosco, Lecturer, Departement of mechanical engineering of Ensai, University of Ngaoundere. boscosamon@gmail.com

Fourth Author - Nzie Wolfgang, Associate professor, Head of Departement of fondamentals sciences and engineering techniques in EGCIM, University of Ngaoundere. wnzie@yahoo.fr

Fifth Author - Tcheukam - Toko Dénis, Associate professor, Head of Departement of mechanical engineering in ColTech, University of Buea. tcheukam-toko@yahoo.fr

Sixth Author - Ali Ahmed, Associate professor, Lectures in IUT, University of Ngaoundere. aliahmed_k10@yahoo.fr

Correspondence Author - Kengne benjamin, benjaminkengne@gmail.com. 